\title{
The Merits and Positive Effects of Exercise on Teenagers, Who Feel Depression
}

\author{
Siraj Nawaz Khan ${ }^{1}$, Usman Sani ${ }^{2}$, Sami Ullah ${ }^{3}$ \\ ${ }^{1}$ Department of Physical Education, SBBU, Upper Dir, Pakistan \\ ${ }^{2}$ Terich Mir Education and Vocational College, Chitral, Pakistan \\ ${ }^{3}$ Department of Economics, University of Peshawar, Peshawar, Pakistan \\ Email address: \\ sami00212@yahoo.com (S. Ullah)
}

\section{To cite this article:}

Siraj Nawaz Khan, Usman Sani, Sami Ullah. The Merits and Positive Effects of Exercise on Teenagers, Who Feel Depression. International Journal of Sports Science and Physical Education. Vol. 2, No. 2, 2017, pp. 29-36. doi: 10.11648/j.ijsspe.20170202.12

Received: June 4, 2017; Accepted: June 16, 2017; Published: July 20, 2017

\begin{abstract}
Depression is a typical issue for youthful grown-ups. Quickly evolving way of life, requests of work and school, harmful occasions, misfortune, and forlornness are quite recently a few components that may contribute the expansion in number of analyzed depressed indications in teenagers. Sick expansion to restorative evaluation and determination by experts, a few specialists are including physical movement as a major aspect of the treatment plan to help with enhancing state of mind. Exercises, for example, yoga, bowing, walking, gardening, swimming and jujitsu might be useful for those fighting mellow sadness. Recognizing the impacts that exercises, a study was conducted in UC Toormang Tehsil Khall, District Dir Lower to find out the causes and effects of depression in teenagers. The role of physical exercise was also studied. Data from 50 male teenagers was collected and analyzed through statistical package SPSS. It was concluded that there are five to six major reasons like falling in love, financial needs, strick educational environment, domestic problems, lengthy working hours and low labor wage of depression in teenagers. It was also concluded that different physical exercise has a positive effect in reducing depression in teenagers.
\end{abstract}

Keywords: Depression, Teenagers, Swimming, Walking, Gardening, Bowing

\section{Introduction}

Background of the study

"Absence of action obliterates the great state of each person, while development and customary physical exercises spare it and look after it" (Plato). Among youthful grownups, dejection is a standout amongst the most usually detailed conditions, and along these lines it is a standout amongst the most examined themes by emotional wellness professionals. Wretchedness as depicted by Pinette (2003) is brought on by a mix of components, for example, hormones, rest propensities, heredity, and substance irregular characteristics inside the mind. The individuals who are discouraged may lose enthusiasm for exercises they normally appreciate, changes in rest cycles, hunger, and sentiments of uselessness [17].

It was noticed that today's teenagers are wealthier more instructed, and more beneficial than at any other time but then there is by all accounts an immense ascent of genuine passionate issues in this populace. The most weight and obligation brought on by juggling work, extracurricular exercises, homework, social life, and different occasions going ahead in the home, for example, a separation of guardians, manhandle or disregard can just improve the probability of drawing in some type of enthusiastic weakness [13].

It has been generally acknowledged that exercises improve individuals feel. Likewise, individuals in the United States are, in general, genuinely inert [1]. It is baffling that it is such a notable conviction, to the point that exercises can improve one feel, however $66 \%$ of grown-up Americans don't take an interest in normal work out. On the off chance that exercises are not a need in many individuals' lives, in what exercises would they say they are locks in?

There are numerous others more pleasurable exercises, for example, eating when ravenous, dozing, and taking part in sexual connections. As indicated that people settle on a large portion of their choices considering their state of mind 
feeling on the specific point in time. $50 \%$ of people which are no longer partake in consistent exercises lean to slump out of their normal, even though the larger part of those people once delighted in and valued the way exercises upgraded their constructive temperament [1].

As indicated by The Harvard Mental Health Letter (2002), young men and young ladies are similarly powerless to wind up distinctly discouraged. It is not until pubescence that young ladies will begin to hint at depression, more so than young men. When they get to be distinctly youthful grownups, young ladies tend to have depressive side effects, all things considered, 2:1 contrasted with young men. Melancholy, regardless of what age the individual, tends to be a repetitive disposition issue, and the individuals who are in treatment stand a decent shot of backslide. For people determined to have gentle gloom, setting up a routine of reliable physical exercises may build the likelihood for development in the people's depressive side effects. Exercises may expand the body temperature and enhance course, modify the cerebrum science by enhancing attitude and making a quieting impact on a person with somewhat depressive indications [20].

Alongside different medicines for gloom, physical exercises may turn out to be the savviest for the individual [21]. Even though there has been research on the constructive outcomes that exercises have on state of mind, the advantages that exercises may have on side effects of despondency is something that has come to fruition lately. As indicated [21] there are three unique speculations that clarify the positive influences exercises have on sadness that incorporate thermogenic, endorphin, and the manoamine neurotransmitter hypothesis. The thermogenic hypothesis expressed that "the pressure lessening related with exercises is thought to be created by the height of body temperature" [21]. The second hypothesis, called the endorphin hypothesis, trusted that chemicals are discharged in the mind that decreases torment while in the meantime it improves the energized condition of work out. In conclusion, the manoamine neurotransmitter hypothesis recommended that depressive side effects are helped by exercises where there is a reconfiguration of the neurotransmitters in the mind [21].

Exercises all the time, even less tiring activity, for example, strolling, has ended up being a powerful treatment gentle sadness [21]. An alternate review by [12] demonstrated that there was a sexual orientation contrast in how exercises expanded or brought down depressive indications amongst guys and females. It was found that females who took an interest in abnormal amounts of exercises did in truth have diminished depressive side effects. Guys who detailed larger amounts of exercises demonstrated an expansion in depressive side effects. There were no solid reasons in the matter of why guys and females had distinctive encounters, yet it was noticed that the specimen size of men was fundamentally lower than that of females. [12] Likewise remarked that "while theoretical, it is conceivable that high exercises levels among gloom inclined guys may speak to a compensatory endeavor to ensure against depressive indications and reestablish sense of pride" (p. 197). During the last 50-60 years, wretchedness has frequently been dealt with by psychotropic drugs, for example, imipramine (a tricyclic), ironized (monoamine oxidase inhibitor), and specific serotonin reuptake inhibitors (SSRI), to give some examples [5]. As more research on dejection surfaced numerous medicines began picking up prevalence. The distinctive medicines appeared as electroconvulsive treatment (ECT), light treatment, and St. John's wort (a home-grown cure). ECT included electrical streams to the skull to initiate a gentle seizure [5]. Light treatment is certain in nature. It is regularly utilized as a part of the treatment of winter depressive indications, and is finished by introduction to manufactured light. St. John's wort is a home-grown supplement that is generally used to treat mellow depressive side effects.

As of late the utilization of exercises as a treatment for melancholy has increased awesome ubiquity. Exercises preparing has frequently been appeared to enhance depressive side effects in sound, non-discouraged specimens" (p. 745). Albeit sound people have less requirement for the alleviation of depressive manifestations, the examination on the individuals who do have direct to extreme despondency should be more entire [5]. A review was led on people who were determined to have mellow depression, and they were partitioned into one of three gatherings. The gatherings comprised of 1) a running gathering, 2) time restricted psychotherapy, and 3) time-boundless psychotherapy [5]. The results from this review discovered that every one of the people included hinted at diminished depressive side effects, and no gathering appeared to be more successful than the other.

There is a scourge of corpulence in Pakistan alongside an expanding populace of people with analyzed melancholy. As per an article in Pakistan diary of nourishment (2012), more than one-thirds of Pakistani is fat, when characterized as the individuals who have a body-mass-file of more than $30 \%$. At the point when psychotropic pharmaceuticals are not accessible either because of monetary reasons or openness, physical exercises might be a suitable, savvy elective. Exercises may likewise enhance an individual's mental selfview, which is particularly essential to awkward teenagers. Additionally, exercises may take many structures including oxygen consuming activity (strolling, running, or ball), and anaerobic work out (weight-lifting, yoga, and karate). The same number of youngsters may not recognize what dejection is or on the off chance that they have side effects of the turmoil, instruction can be extremely helpful to the individuals who may require it. The issue consequently gets to be, for adolescents who are battling with mellow sorrow, are there financially savvy approaches to lessen the side effects and enhance inclination that work alongside the restorative treatment get ready for young depression.

The importance of the present review is to think about the part of physical exercises and its impact on wretchedness in youthful grown-ups in the range of Toormang, Tehsil Khall. Another hugeness is to survey the writing and gather 
information to decide the potential advantages exercises may have on teenagers who are determined to have mellow dejection or who have starting phases of depressive side effects. To examine different exercises for consciousness of the youthful and empower grown-ups for physical exercises in Toormang. The Government, Local and worldwide association and neighborhood group alongside nearby government will concentrate on these exercises for youngsters.

\section{Objectives of the Study}

The research was conducted considering the following Objectives:

(1) To find out the major causes of depression in teenagers in UC Toormang Tehsil Khall.

(2) To analyze the effects of physical exercise on depression in teenagers in the study area.

(3) To suggest different exercises which would likely to reduce depression in teenagers.

\section{Justification of the Study}

The Physical exercise is a physical action that promotes and helps in the maintenance of fitness of body and overall health of an individual. The same topic was selected because most of the diseases like depression are caused by lack of physical exercise. Many of the people in the society, of the group teenagers, have high depression. That's why this study was conducted in Union Council Toormang, Tehsil Khall, District Dir Lower.

\section{Literature Review}

It will be found in chapter II that there will be five areas relating to depression. The primary area will be: commonness of depression, age inconsistencies, sex contrasts, and battle will be introduced. The second most prominent reason for misery and the different variables that may add to the muddle will be seen. The $3^{\text {rd }}$ is that the reader will analyze the many sorts of exercise that are accessible to decrease the side effects of depression. Fourth, a point of view will be displayed which incorporates a concise portrayal of option perspectives on exercise and its consequences for depression. At long last, in the last area, the reader will be furnished with an outline of the exploration that as of now exists on the theme.

Among youthful grown-ups, melancholy is the most ordinarily announced issue, and in this manner, it is a standout amongst the most points by emotional wellness specialists [14]. To help teenagers comprehend sorrow and its side effects, a survey was given to the members asking: "have you ever felt so dismal or miserable practically consistently, for two weeks in a month that you can't do some of your typical exercises?" (p. 5). More than $30 \%$ of the female members proclaimed they have felt along these lines, and more than $20 \%$ of the male members announced they had encountered this kind of outrageous trouble sooner or later. With the consequences of the study, the specialists could extend that about one in four teenagers are influenced by mellow melancholy [14].

In a review that analyzed the impacts of specific activities on uneasiness and misery in understudies, the analysts found that there were no prompt outcomes, in any case, following an eight-week trial, they found that there were sure emotional (inclination) changes in the understudies in view of the usage of work out [6]. "There are an assortment of physical activities, for example, running, swimming, and yoga that have a specific impact of enhancing mind-set states, for example, dejection and tension" [6].

As indicated by [15] there are some significant reasons for gloom that may incorporate psychosocial push, genuine or stretched disease, real way of life modifies, or knowledge of a stunning occasion. Lauber characterized psychosocial worry as mental strain that is brought on by unapproachable desires, peer weight, or potentially bum-out, which is knowledgeable about the home, school or in the working environment [15]. Lauber went ahead to state that those included in the review clarified that a traumatic occasion was the reason for misery in their lives. A traumatic occasion could incorporate battle benefit amid a war, tropical storm or tornado aggravations, physical assault or assault, and here and there movement because of vagrancy or loss of employment. The scientist closed most of the members in their review had acquired depressive side effects that originated from a sickness or infection that could have incorporated different unsuccessful surgeries, obscure ailment or considerably disease. Although many reasons for dejection were recorded all through the review, the analysts additionally found that there was no connection amongst socioeconomics and wretchedness and the discoveries were summed up to different populaces [15].

As indicated by Bower (2003), "around 34 million people in the United States had sooner or later experienced significant depression, and approximately 13.5 million individuals endured episodes of extreme dejection" (p. 29). These numbers demonstrate that around $23 \%$ of the United States populace experiences depression. Even though those numbers seem high, it does exclude the individuals who experienced mellow to direct wretchedness, or the numerous people who went undiscovered as they didn't perceive the indications of sorrow. It is critical to advise school staff about the predominance of despondency in youthful grown-ups, to some extent because of the higher likelihood of suicide related with untreated misery [4].

Thinks about have demonstrated that in immature guys, approximately 11.4 for every beyond words suicide, and their technique is more probable by the utilization of a gun [2]. Even though the quantity of male suicides is more prominent than that of females, the quantity of endeavored suicides and analyzed despondency was superior for females. Beall (2000) went ahead to state that the quantity of passing expanded in the smaller amount of inhabited areas of the nation, for example, the intermountain west. It shows the reason to some 
extent because of the separation, detachment, and harsh climate people in that district may have encountered.

Beall likewise decided there was a $20-30 \%$ possibility that individuals with sadness were probably going to create bipolar turmoil, and many others mental issue. Some kids were found who have guardians who battle with real depression may have a half shot of having dejection themselves. Another calculate of gloom discovered indistinguishable twins was whether one had sadness, it was likely the other would have melancholy also [2].

There are numerous people in this nation determined to have significant sorrow. As indicated by [18] there are roughly 80 million individuals who have looked for some type of guiding for depressive side effects. The analysts showed that sadness is the most predominant psychological well-being turmoil, and by a wide margin is the most analyzed by medicinal specialists.

Notwithstanding the reasons for melancholy, already talked about, there are other a few clarifications and hypotheses. A rundown of potential foundations for gentle melancholy were recognized in The Harvard News Letter (2002), including sadness coming about because of death or separation of guardians, a failure to experience the exclusive standards of guardians, not having the capacity to comply with unattainable ethics or goals, absence of passionate bonds because of dismissal or disregard, accepting a lot of feedback and additionally discipline, and sexual or physical mishandle, bringing on the young people to have a powerlessness to control stretch levels. Adolescents and youthful grown-ups may likewise have trouble with making a self-character, as amid pubescence many still cling to their adolescence propensities. This is a troublesome time in a youngster's life because of the passionate, scholarly, and physical moves that are happening so quickly. Additionally, a youngster's hormones change so quickly making sexual strain, that regularly they can't adapt to the driving forces they encounter [20].

An incredible lion's share of the examination relating to reasons for mellow misery identifies with hereditary qualities and inherited demeanor, as a standout amongst the most acknowledged clarifications for depression. Teenagers and youthful grown-ups have tantamount rates of despondency to that of grown-ups, which was evaluated between $6 \%-9 \%$ in the United States [20]. "The hereditary commitment to inclination issue is particularly high when the indications first show up in adolescence or teenagers" [20]. It was additionally expressed in the bulletin that over half of kids with a parent who had a background marked by significant sadness have an affair of misery themselves. Inside this examination, hereditary qualities were introduced as natural variables adding to sorrow as received youngsters were infrequently observed to be more discouraged because of organic foundation instead of the earth. In the event, everyone/person has its own family background of liquor abuse or identity issue, the odds of gloom expanded exponentially [20].

Although hereditary qualities are a central point, it is only one reason for gloom scientists have found. A people's domain (companions, family, accomplices, and way of life) are additionally potential supporters to the probability of getting to be distinctly discouraged [23]. On the off chance that a teenager lives in a discouraging situation encompassed by other people who battle with state of mind issue, they may get on the trouble and make it a piece of their way of life as well. Having solid good examples who can adapt to life's difficulties may help young person's battle side effects of gentle wretchedness. Picking exercises with companions that may incorporate computer games with a load of viciousness may build the shot for gloom as they should create social aptitudes and have open air time adjusted with stressinitiating computer games or films. Teenagers need to settle on great way of life decisions for solid points of view on the world keeping in mind the end goal to disguise the qualities and standards related with sound states of mind.

Wage turns into a variable for sadness when the individual battles to bolster himself/herself, and if there are wards it makes it much more troublesome. Living in a situation where road brutality is an ordinary event may build the odds a teenager could get to be distinctly frightful and create uneasiness or melancholy. Loss of occupation and pay may likewise add to sorrow inside the family on the off chance that they are destitute and hungry. Without medicinal protection, different families may perceive indications of depression, however may not know where to turn for budgetary help or restorative exhortation. Most of the time numerous youthful grown-ups might not have the assets important to adapt to the anxiety that neediness may bring, and dejection can be a reasonable result.

The Harvard News Letter (2002) additionally talked about how youthful grown-ups who are gay person are at an essentially higher danger of getting to be distinctly discouraged because of difficulties they look, for example, segregation and social shame, with companions, family, and group individuals who show cold-heartedness. At such a critical time in life, it is particularly difficult and mistaking for somebody who is gay person to live in a culture where it is viewed as unthinkable or revolting. Teenagers who are scrutinizing their sexual personality may think that it's accommodating to converse with trusted grown-ups about the issue to find out about group asset offices and think about groups to asses them with their sentiments.

It has been noticed that while today's youngsters are wealthier, more instructed, and more advantageous than at any other time there is by all accounts a mind-boggling ascent of genuine enthusiastic issues in this populace. Kids who are tormented or pestered at school and insulted or prodded by others may make a domain that makes bitterness and weakness. Modem innovation that offers smut, digital tormenting, and improperly utilized interpersonal organizations that spread gossipy tidbits and untruths may additionally add to the mind-boggling pity of youthful grown-ups today. The enormous weight and duty brought on by juggling work, extracurricular exercises, homework, and a requesting social life may additionally confound the lives of 
young people. Occasions experienced at home that may incorporate a separation or division of guardians, living a large portion of seven days at one home and the next part of the week at home of other parents while juggling plan requests of work and school can just improve the probability of pulling in some type of enthusiastic hindrance [13].

[13] broadly expounded separation and its negative impacts on the youngsters that are included, finding when guardians do choose to separate the odds of the kid investing more energy alone increments essentially. Even though young people may state they need to be allowed to sit unbothered, and appear to fear investing energy with their folks, regardless they want consideration and love from their folks. "Dejection makes a passionate vacuum that is filled by an exceptional associate culture, a basic cradle against children's dread of detachment. Some dependence on companions for support and acknowledgment is impeccably ordinary, however if guardians relinquish their obligations of giving structure and limits, youngsters may tend to shape their own arrangement of tenets. At the point when young people encounter unreasonable seclusion by their folks, they are more defenseless to genuine passionate issues [13].

Undergrads are one of the most noteworthy populaces that display uneasiness and dejection, and this might be because of the thorough way of life many leads. Since going to class, taking tests, doing homework, holding an occupation and having a conflicting rest plan, numerous undergrads may have large amounts of nervousness and sorrow. The physical and mental exercise that was talked about in the review was jujitsu chuan, which was proficient through a progression of moderate and elegant developments. Jujitsu chuan was intended to exercises the body through the arrival of strain by unwinding and having an unmistakable personality to lessen push levels and gentle melancholy. This sort of exercises was composed as mental control, which is the reason kendo chuan would give positive outcomes in the decrease of depressive manifestations [6].

It is basic that option methods of treatment are given to people who experience the ill effects of despondency. As indicated by [8] those with melancholy burned through oneand-a half circumstances more a year on medicinal services than people who did not encounter depressive manifestations. They likewise burned through three circumstances more on stimulant drug than the individuals who did not have to use outpatient pharmaceutical administrations. Exercises may give a workable, modest supplement to medicinal treatment for gentle depression.

There are certain connections reported amongst exercises and melancholy since the mid 1900's. Two gatherings of people with analyzed dejection were separated into a direct and high forces assemble. A portion of the general population indicated enhanced state of mind and others were exhausted. It was resolved that understudies because the execution of work out [6]. "There are an assortment of physical activities, for example, running, swimming, and yoga that have a specific impact of enhancing inclination states, for example, wretchedness and tension" [6].
The article Depression and Exercise (2005) broadcasted that if a single activity for 30 minutes' day by day, their general temperament will enhance significantly. Any type of exercises would be satisfactory, the length of it was done reliably. A run around the recreation center, or something even less tiring, for example, cultivating appeared to help people bring down their depressive indications. "Once more the outcomes from formal trials are blended, however there's genuinely great confirmation that exercises are gainful for mellow to direct gloom" [10]. At the point when people worked out, endorphins were discharged all through the body, which are little chemicals that go about as torment executioners, and will take the individual into a cheerful. With standard work, out, depressive indications diminished in expansive part because of dozing better, managing more vitality for the duration of the day, and having a superior feeling of self-regard in the wake of working out.

Fusing exercise into one's every day routine could likewise have other medical advantages, for example, needing to eat more beneficial and quit smoking, which thusly made a more advantageous way of life through and through depression. The article Teen Depression expressed that teenagers and youthful grown-ups who experience the ill effects of melancholy may wish to look for a supportive kind of treatment, regardless of whether it is singular, gathering, family, or some other shape treatment, to help fight despondency. Including the entire family in treatment can make a superior comprehension of the condition and enhance the correspondence, comprehension and sympathy among individuals. Support in treatment could help the individual perceive and change adverse musings, decide constructive approaches to issue illuminate, and secure fitting social and interpersonal abilities (Teen Depression). [22] the writers depicted how diagnosing youngsters with gloom is an exceptionally troublesome undertaking. Teenagers tend to show exercises that may concur with the individuals who have depressive side effect otology, for example, being anxious, shaky, and excessively passionate. In the past there have been normal convictions that when adolescents do hint at sorrow, it is taken a gander at as being average conduct or a phase he/she is experiencing. Some have alluded to this as run of the mill high school hormones or touchiness.

In a review directed for over 10 years on around 400 young people determined to have depression, teenagers were separated into four gatherings and given distinctive treatment regimens. The main gathering was given Prozac, the second was treated with Cognitive Behavioral Therapy (CBT), the third had a blend of Prozac and CBT, and the fourth gathering was treated with a fake treatment. Subjective Behavior Therapy is a standout amongst the best medications for misery in grown-ups, yet this review uncovered this was not generally valid for young people. The best treatment was the blend of Prozac with the CBT. It was prescribed that CBT be the principal line of safeguard before different types of treatment are tried. Additionally, it was expressed that everyone is novel and may react contrastingly to treatment [22]. 
Even though exercises can improve numerous people feel, there are other antagonistic symptoms that exercises have also. After intense workouts people, can feel agony, solidness and soreness. Others encounter a type of fixation on exercises that can get to be distinctly unfortunate as well. Overpracticing to the point of making harm, dietary issues or wellness fixation seems to expand despondency related side effects. Practicing an excess of is not something to be thankful for when it gets to be distinctly over the top. As expressed beforehand, exercises can be a financially savvy answer for misery; be that as it may, snappy settle arrangements can likewise be extremely costly. Consistently there is by all accounts another contraption that ensures lean abs, or a supernatural occurrence shake that sheds the pounds in a matter of weeks, all of which can prompt to a misguided feeling of trust, and purge wallets [1].

Although there are numerous positive advantages to consistent work out, there are some insufficient projects that ought to be stayed away from keeping in mind the end goal to see durable outcomes. Adopting Exercise to reduce depression is viable for some adolescents who are looking for alternatives other than or in association with prescription. Adolescents ought to counsel a doctor before beginning exercises program and ought to keep on following specialist's requests with respect to any drug. Beginning bit by bit and outlining little victories my help teenagers have yet another technique to work through early phases of gentle wretchedness side effects.

\section{Methods and Materials}

\subsection{Universe of the Study}

Union council Toormang 1 was selected for data collection and research on the selected topic. Toormang area was selected based on high crime ration among teenagers. Also, me myself belong to that area so was easier for me to collect data and directly observe the situation of the teenagers. Also, Toormang 1 has diversity in tribes and occupation.

\subsection{Sampling}

A sample of 50 male respondents between age group 1319 was selected randomly from the overall population of teenagers in the study area. It was assumed that each of the resp[ondent ws facing depression due to different reasons.

\subsection{Data Collection}

The research was based on primary data that was collected from the randomly selected male respondents only through well-structured close ended questioners. The questioners comprise Likert type questions. The data was collected by the researcher himself.

\subsection{Data Analysis}

The primary data collected from the respondent were analyzed as descriptive statistics through SPSS and Excel and were presented in tables, pie charts, line charts and frequency tables etc.

\subsection{Limitations}

The study been conducted having certain limitation. Sample size of 50 respondents was taken from the population that is not enough but due to time constraint it was not possible to maximize the number. Another limitation was, only male teenagers were selected for the study ignoring the female due to cultural constraint.

\subsection{Conceptual Framework}

Table 1. Conceptual Framework.

\begin{tabular}{ll}
\hline Independent variable & Dependent variable \\
\hline $\begin{array}{l}\text { Those variables which are changed } \\
\text { by the researcher during } \\
\text { experiment. }\end{array}$ & $\begin{array}{l}\text { These variables are changed as the } \\
\text { independent variable is changed. }\end{array}$ \\
$\begin{array}{l}\text { It is commonly represented by ' } x \text { ' } \\
\text { It shows the action that a }\end{array}$ & $\begin{array}{l}\text { It is normally represented by ' } y \text { ' } \\
\text { change. }\end{array}$ \\
$\begin{array}{l}\text { The researcher manipulates its } \\
\text { vale. }\end{array}$ & $\begin{array}{l}\text { Its value is also manipulated by the } \\
\text { change in the independent variable. }\end{array}$ \\
$\begin{array}{ll}\text { researcher but during experiment. } \\
\text { Its value can't be changed but } \\
\text { changed due to change in the }\end{array}$ \\
\hline
\end{tabular}

\section{Results and Discussion}

\subsection{Demographic Characteristics of the Respondents}

Table 2. Demographic characteristics of Respondents.

\begin{tabular}{lll}
\hline Factor & Sample size $\mathbf{( N )}=\mathbf{5 0}$ & Percentage (\%) \\
\hline $\begin{array}{l}\text { Gender } \\
\text { Male }\end{array}$ & 50 & 100 \\
Female & 0 & 0 \\
Age of Respondents & & \\
$13-16$ & 34 & 68 \\
$17-19$ & 16 & 32 \\
Marital Status & & \\
Unmarried & 50 & 100 \\
Educational status & & \\
Nil & 4 & 8 \\
Primary & 29 & 58 \\
Metric & 17 & 34 \\
\hline
\end{tabular}

The above table shows that all the respondents were male $(\mathrm{N}=50)$ that is $100 \%$ of the sample. Respondents were divided into two age groups i.e. 13-16 which was $68 \%$ and $32 \%$ were in the range of $17-19$. All the respondents were unmarried $(\mathrm{N}=50)$ making $100 \%$ of the total sample size. Fourth category indicates educational status of the respondent which was further divided into three categories i.e. Nil (respondents with no education), primary and metric. Respondent having no education at all were 4 in numbers (8\%). Those having primary education were $29(58 \%)$ and respondents having education up to metric were 17 (34\%)

\subsection{Number of Respondents with Depression}

The figure given below shows number of respondent having depression. Further figure shows in the table that 
among 50 respondents, 37 were found having symptoms of depression which is significant.

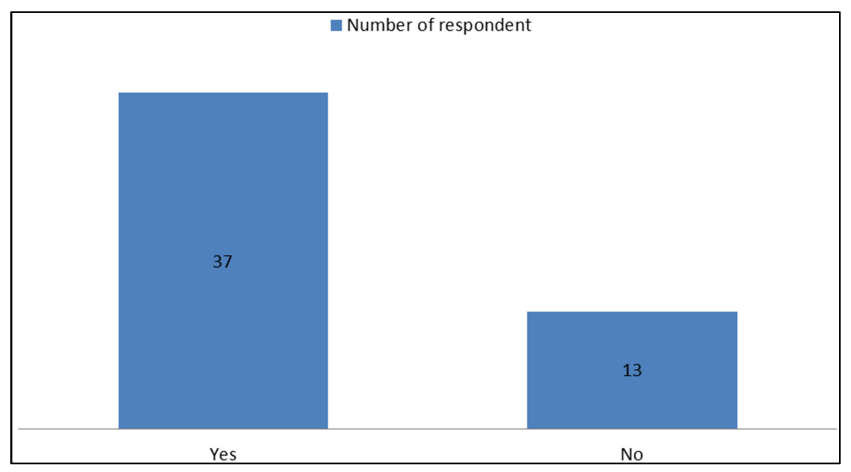

Figure 1. Number of the Respondent with depression.

\subsection{Reason of Depression in Teenagers}

Figure 2 shows the reason of depression that was financial problem, domestic problem, low labor wage, educational stress, love, and lengthy working time.

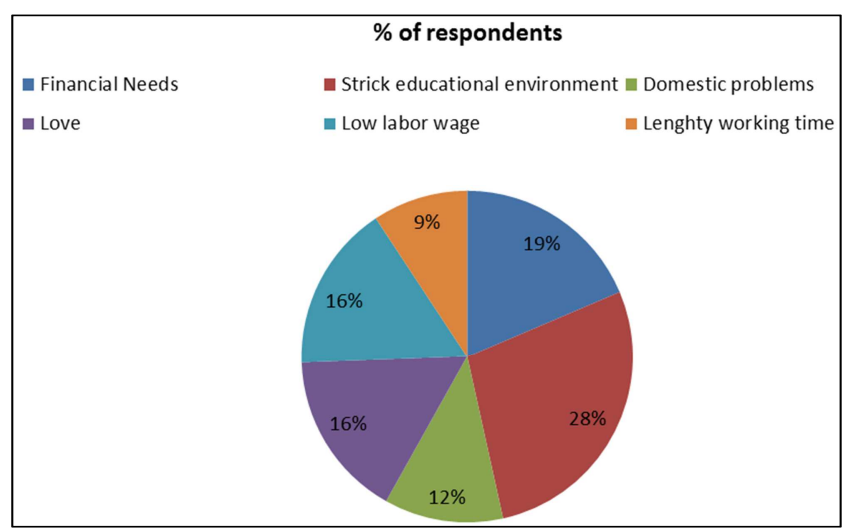

Figure 2. Reason of depression in teenagers.

\subsection{Ratio of Physical Exercise Reducing Depression in Teenagers}

Figure 3 shows that exercise have a positive effect in reducing depression. Physical exercises reduce depression of 45 respondents out of 50 .

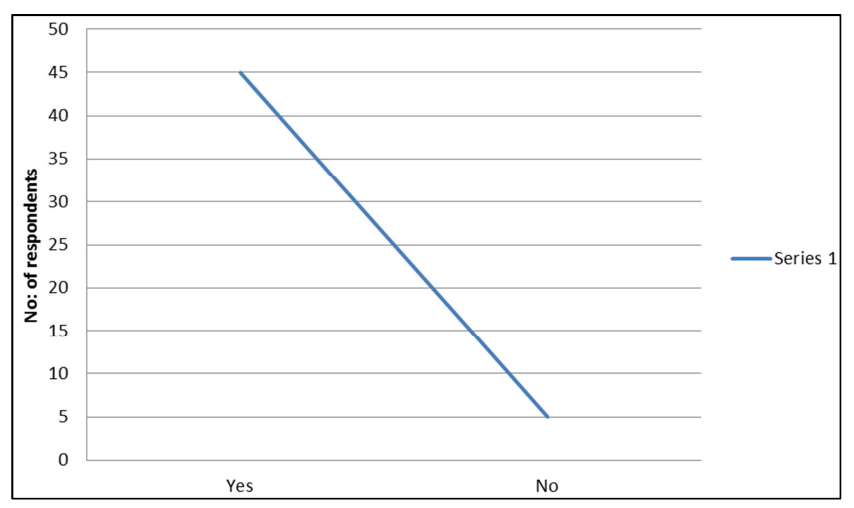

Figure 3. Physical exercise reducing depression in teenagers.

\subsection{How Might Physical Exercise Reduce Depression}

The table below explains the ways through which physical exercise reduces depression in teenagers in the study area.

Table 3. Ways physical exercise reduces depression in teenagers.

\begin{tabular}{lll}
\hline S. NO & $\begin{array}{l}\text { Number of } \\
\text { respondents }\end{array}$ & $\begin{array}{l}\text { How Physical Exercise reduce } \\
\text { depression }\end{array}$ \\
\hline 1 & 22 & Diverting concentration \\
2 & 14 & Gathering with friends \\
3 & 5 & Increases blood flow to brain \\
4 & 3 & Functionalize stomach \\
5 & 6 & Refreshment \\
\hline
\end{tabular}

\subsection{Best Exercise that Reduce Depression in Teenagers}

Figure 4 below explains that cricket is on the top to reduce depression following by volley ball, jogging, running and football.

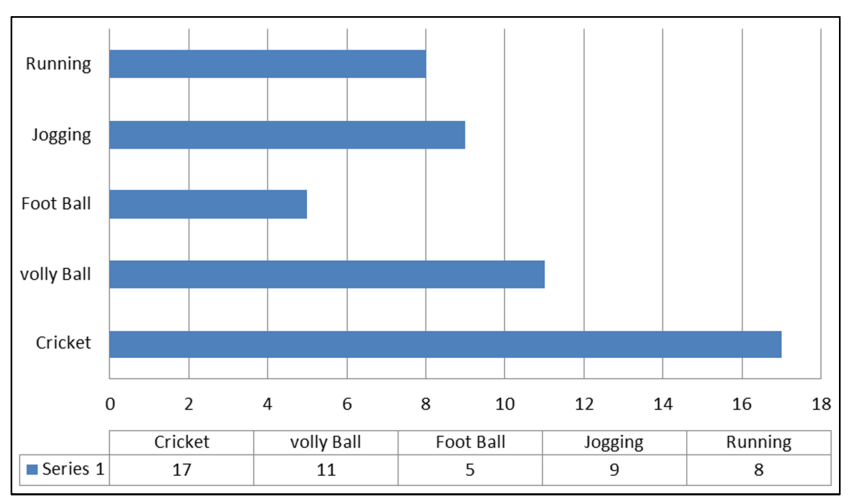

Figure 4. Best Exercise to reduce depression in teenagers.

\section{Finding, Conclusion and Recommendation}

\subsection{Major Findings}

Depression is one of the main mental issues that effects people the country over; consequently, the subject of exercises and its impacts on sadness in youthful grown-ups was chosen. The insights on depression uncovered some startling numbers on what number of youngsters fights with sadness in US. [14] Had expressed that almost one fourth of the country's young grown-ups are beset with sadness. It is vital that teenagers be filtered for depression as a piece of the consistent therapeutic registration. Females outnumbered guys somewhat in detailed wretchedness. Because of the high rate of endeavored suicide in teenagers it is critical that they get therapeutic evaluation and behavior identified with manifestations of depression.

The writing demonstrated many reasons for misery including hereditary qualities, condition, and way of life, delayed sickness, and unpleasant occasions. To find out if there are any chances of depression in teens in Toormang area of Tehsil Khall and as there any exercises like physical exercise adopted by the persons with depression for reducing it. If depression prevails in teenagers in the study area, then 
what should be done to reduce the depression? A study was conducted in the month of July to Nov 2016 in the abovementioned area.

Primary data from 50 respondent's teenagers was collected through well-structured close ended questionnaire. During the research, it was find out that most of the teenagers are facing the problem of mental depression due to financial needs, domestic problems, low labor wage, strict educational environment, love and lengthy working time. $19 \%$ teenagers have depression due to financial needs, $12 \%$ teenagers have depression due to domestic problems, $16 \%$ teenagers have depression due to low labor wage, $28 \%$ teenagers have depression due to strict educational environment, $16 \%$ teenagers have depression due to falling in love and $9 \%$ teenagers have depression due to lengthy working time.

\subsection{Conclusion}

It was concluded that the teenagers use to reduce their depression by playing games like cricket, volleyball, football, jogging and running. Game reduces depression in teenagers in the study area by diverting concentration 22 (44\%), gathering with friends 14 (28\%), increasing blood flow to brain 5 (10\%), functionalizing stomach $3(6 \%)$ and refreshment $6(12 \%)$. In total of 50 respondents, $11(22 \%)$ replied that use to play volley ball to reduce their depression, $5(10 \%)$ replied that use to play football to reduce their depression, $9(18 \%)$ replied that use to do jogging to reduce their depression and $8(16 \%)$ replied that use to do reduce their depression,

So, it was conducted that there is a positive relationship between depression and physical exercise. Physical exercise plays a significant role in reducing depression in teenagers in area of Toormang Tehsil Khall.

\section{References}

[1] Backhouse, S. H., Ekkekakis, P., Biddle, S., Foskett, A, \&Williams, C. (2007). Exercise makes People feel better but people are inactive: Paradox or artifact. Journal of Sport \&Exercise Psychology, 29, 498-503.

[2] Beall, S. (2000). Talking with teens: Successfully screening for high risk behavior. JSPN, 5, 139-142.

[3] Bodin, T., \& Martinsen, E. W. (2004). Mood and self-efficacy during acute exercise in clinical Depression: A randomized, controlled study. Journal of Sport \&Exercise Psychology, 26, 623-633.

[4] Bower, B. (2003). U.S. survey probes depression care. Science News, 164, 29. 22.

[5] Brosse, A L., Sheets, E. S., Lett, H. S., \& Blumenthal, J. A (2002). Exercise and the treatment of Clinical depression in adults: Recent findings and future directions. Sports Medicine, $32,741-760$.

[6] Cal, S. (2000). Physical exercise and mental health: A content integrated approach in coping with College students' anxiety and depression. Physical Educator, 57, 69-79.
[7] Can food lift your spirits? (2005, February). Time Canada, 168. Retrieved April 7, 2008, from: Ebsco host database.

[8] Craft, L. L., \& Landers, D. M. (1998). The effect of exercise on clinical depression and depression resulting from mental illness: A meta-analysis. Journal of Sport \&Exercise Psychology, 20, 339-357.

[9] Depression and exercise: How the body fights depression naturally. Retrieved Apri114, 2008, from: www.depressionhelp-treatment.com/depression-and-exercise.

[10] Depression and exercise: Exercise effects depression in many ways. (2005). Retrieved April 7, 2008, from: www.depressionguide.comldepression-and-exercise.

[11] Georgia State University. (1998). The exercise and physical fitness page. Retrieved March 5, 2008.

[12] Joiner, T. E., \& Tickle, J. J. (1998). Exercise and depressive and anxious symptoms: What is the nature of their interrelations? Journal of Occupational Rehabilitation, 8, 191198.

[13] Kantrowitz, B., \& Wingert, P. (2008). How well do you know your kid? Newsweek. Retrieved Apri114, 2008, from: www.newsweekcomlid/88250/output/print.

[14] Knopf, D., Park, M. J., \& Mulye, T. P. (2008). The mental health of adolescents: A national profile, 2008. San Francisco, CA: National Adolescent Health Information Center, University of California. 23.

[15] Lauber, C., Falcato, L., Nordt, C., \& Rossler, W. (2003). Lay beliefs about causes of depression. Acta Psychiatr Scand, 108, 96-99.

[16] Obesity in America. (2007, September). Time, 170, 16. Retrieved April 14, 2009, from: Ebsco host database.

[17] Pinette, G. (2003). The goods on herbal depression treatment. Windspeaker, 21. Retrieved April 7, 2008, from: Ebsco host database.

[18] Ponterotto, J. G., Pace, T. M., \& Kavan, M. G. (1998). A counselor's guide to the assessment of depression. Journal of Counseling and Development, 67, 301-310.

[19] Teen Depression. (n. d.). Adolescent depression treatment. Retrieved April 7, 2008, from: www.teendepression.org/articles4.

[20] The Hardvard Mental Health Letter. (2002). Depression in children - Part L 18, 1-8.

[21] Tkachuk, G. A, \& Martin, G. L. (1999). Exercise therapy for patients with psychiatric disorders: Research and clinical implications. Professional Psychology: Research a Practice, 30, 275- 282.

[22] Youth: a different way of healing. (2007, October). Newsweek. Retrieved April 14, 2008, from: www.newsweekcomlid/54057/output/print.

[23] Zeman, S. (1996). Researching the causes of depression: Reasons for optimism. International Review of Psychiatry, 8, 403-407. 